\title{
INFLUÊNCIA DA SATURAÇÃO POR BASES DO SUBSTRATO NO CRESCIMENTO E QUALIDADE DE MUDAS DE Machaerium nictitans (VELL.) BENTH. ${ }^{1}$
}

\author{
Paulo Henrique de Souza ${ }^{2}$, Haroldo Nogueira de Paiva ${ }^{3}$, Júlio Cesar Lima Neves ${ }^{4}$, José Mauro Gomes ${ }^{3}$ e \\ Lissandra Silva Marques ${ }^{2}$
}

\begin{abstract}
RESUMO - Este trabalho foi desenvolvido com o objetivo de verificar a influência da saturação por bases do substrato no crescimento e qualidade de mudas de Machaerium nictitans. O delineamento utilizado foi em blocos ao acaso com quatro repetições. Como substrato foram empregados três diferentes solos, sendo em cada um deles a saturação por bases original elevada para os seguintes valores: Argissolo Vermelho-Amarelo 50, 60 e 70\%, Latossolo Vermelho-Amarelo distrófico 30, 50 e 70\% e Latossolo Vermelho-Amarelo álico 25,45 e $65 \%$. Foram avaliadas as características morfológicas das mudas, altura da parte aérea e diâmetro do coleto; peso de matéria seca da parte aérea, raízes e total, bem como as relações entre a altura da parte área e o diâmetro do coleto, altura da parte aérea e seu peso de matéria seca, peso de matéria seca da parte aérea e peso de matéria seca das raízes; e o índice de qualidade de Dickson. Com base nos dados, foi possível concluir que: as melhores mudas de Machaerium nictitans no Argissolo Vermelho-Amarelo foram obtidas na saturação por bases de $60 \%$, no Latossolo Vermelho-Amarelo distrófico na saturação por bases de $70 \%$ e no Latossolo Vermelho-Amarelo álico na saturação por bases de $40 \%$.
\end{abstract}

Palavras-chave: Espécies florestais nativas, solos ácidos e características morfológicas.

\section{INFLUENCE OF SUBSTRATUM BASE SATURATION ON SEEDLING GROWTH AND QUALITY OF Machaerium nictitans (VELL.) BENTH.}

\begin{abstract}
This work was carried out to verify the effect of substratum base saturation on seedling growth and quality of Machaerium nictitans. A complete randomized design with four replicates was utilized. Three different soils were used as substratum, and, in each, the original saturation was raised to the following values: Red-yellow Clay soil, 50, 60 and 70\%, Red-yellow Dystrophic Latosol, 30; 50 and 70\%; and Red-Yellow alic Latosol 25; 45 and 65\%. The morphological parameters of the seedlings, height of the aerial part, stem diameter, dry matter of the aerial part, roots and total were tested, as well as the relation between height of the aerial part and stem diameter, height of the aerial part and its dry matter weight, dry matter weight of the aerial part and dry matter weight of the roots and the Dickson's quality index. Based on the data obtained, it was concluded that the best seedlings of Machaerium nictitans were obtained at the following base saturation values: at 60\% on the Red-Yellow Clay soil, at 70\% on the Red-Yellow Dystrophic Latosol, and at $40 \%$ on the Red-Yellow alic Latosol.
\end{abstract}

Keywords: Native forest species, acid soils and morphological characteristics.

\footnotetext{
${ }^{1}$ Recebido em 15.08.2006 e aceito para publicação em 20.02.2008.

${ }^{2}$ Programa de Pós-Graduação em Ciência Florestal da UFV. E-mail : <phsufv@yahoo.com.br>, <lissandramarques@ yahoo.com.br>.

${ }^{3}$ Departamento de Engenharia Florestal da Universidade Federal de Viçosa (UFV) - Viçosa-MG. E-mail : <hnpaiva@ufv.br>.

${ }^{4}$ Departamento de Solos da UFV. E-mail : <julio_n2003@yahoo.com.br>.
} 


\section{INTRODUÇÃO}

Grande parte dos solos do Estado de Minas Gerais e, notadamente, os presentes no bioma Cerrado, mesmo dotados de boas propriedades físicas, apresentam, em geral, características químicas indesejáveis para o cultivo de vegetais, como elevada acidez, altos teores de alumínio trocável e baixa disponibilidade de nutrientes como Ca, Mg e P (CFSEMG, 1999). A omissão da calagem pode comprometer seriamente a produtividade e o uso eficiente de fertilizantes, sendo tal prática considerada como essencial (CAMARGO et al., 1997).

Em razão da grande variabilidade genética observada nas florestas e em face da heterogeneidade dos solos das regiões tropicais são, ainda, incipientes os dados de pesquisa disponíveis sobre o requerimento nutricional de espécies florestais nativas e a sua capacidade de adaptação a condições ambientais distintas (FURTINI NETO et al., 1999).

Pertencente à família Leguminosae-Papilionoideae, Machaerium nictitans apresenta como nomes comuns bico-de-pato, cauvi, gaximbé e jacarandá-de-espinho, entre outros. Quando em estádio adulto, sua altura varia entre 8 e $18 \mathrm{~m}$, e o tronco pode atingir entre 40 e $60 \mathrm{~cm}$ de diâmetro. As suas folhas são compostas imparipenadas e estipuladas, com 11 a 35 folíolos pubescentes na posição inferior do limbo. Ocorre no Sul da Bahia e nos Estados do Espírito Santo, São Paulo, Minas Gerais e Rio Grande do Sul. Aárvore fornece ótima sombra e pode ser empregada no paisagismo. Como planta pioneira adaptada à luz direta é muito rústica, sendo ótima para plantios mistos em áreas degradadas e de preservação permanente (LORENZI, 1992).
Este trabalho teve como objetivo estudar a influência de diferentes níveis de saturação por bases no crescimento e qualidade de mudas Machaerium nictitans em três diferentes solos.

\section{MATERIAL E MÉTODOS}

O experimento foi conduzido em casa de vegetação no Viveiro de Pesquisas do Departamento de Engenharia Florestal da Universidade Federal de Viçosa, situado nas coordenadas geográficas $-20^{\circ} 45^{\prime} 25,0$ ' de latitude sul e $-42^{\circ} 51^{\prime} 11,0^{\prime \prime}$ de longitude oeste, a $658 \mathrm{~m}$ de altitude, e compreendeu o período de novembro de 2004 a junho de 2005.

Como substrato foram utilizados três diferentes solos: Argissolo Vermelho-Amarelo, um Latossolo Vermelho-Amarelo distrófico e um Latossolo VermelhoAmarelo álico, retirados na camada entre 0,2 $\mathrm{m}$ e 1,0 $\mathrm{m}$ de profundidade, cujas características químicas são apresentadas no Quadro 1. Os solos foram peneirados em malha de $5 \mathrm{~mm}$ e secos ao ar; posteriormente, foram pesadas porções de $2,1 \mathrm{~kg}$ de solo e colocadas em sacos plásticos sobre a bancada da casa de vegetação, no qual permaneceram incubados por um período de 30 dias, sendo realizada a reposição de água nos solos duas vezes ao dia, a fim de manter a umidade em torno de $60 \%$ da capacidade de campo.

Uma mistura de $\mathrm{CaCO}_{3}$ e $\mathrm{MgCO}_{3}$, na relação estequiométrica 4:1, foi utilizada para elevar a saturação por bases dos solos para diferentes valores (Quadro 2), de acordo com a seguinte fórmula:

$$
\mathrm{NC}(\mathrm{t} / \mathrm{ha})=\left(\mathrm{V}_{2}-\mathrm{V}_{1}\right) \mathrm{T} / 100
$$

Quadro 1 - Análise química dos solos utilizados no experimento Table 1 -Chemical analysis of the soils utilized in the experiment

\begin{tabular}{|c|c|c|c|c|c|c|c|c|c|c|c|c|}
\hline \multirow[t]{2}{*}{ Solo } & \multirow{2}{*}{$\begin{array}{l}\mathrm{pH} \\
\mathrm{H}_{2} \mathrm{O} \\
\end{array}$} & $\mathrm{P}$ & $\mathrm{K}$ & $\mathrm{Ca}^{2+}$ & $\mathrm{Mg}^{2+}$ & $\mathrm{Al}^{3+}$ & $\mathrm{H}+\mathrm{Al}$ & SB & $(\mathrm{t})$ & $(\mathrm{T})$ & V & $\mathrm{m}$ \\
\hline & & \multicolumn{2}{|c|}{$\mathrm{mg} \mathrm{dm}^{-3}$} & \multicolumn{7}{|c|}{$\mathrm{cmol}_{\mathrm{c}} \mathrm{dm}^{-3}$} & \multicolumn{2}{|c|}{$\%$} \\
\hline $\begin{array}{l}\text { Argissolo Vermelho- } \\
\text { Amarelo }\end{array}$ & 5,64 & 1,50 & 16,00 & 1,74 & 0,17 & 0,00 & 3,00 & 1,95 & 0,33 & 4,95 & 39,40 & 0,00 \\
\hline $\begin{array}{l}\text { Latossolo Vermelho } \\
\text { Amarelo distrófico }\end{array}$ & 5,40 & 2,50 & 26,00 & 0,17 & 0,09 & 0,00 & 2,00 & 0,33 & 1,95 & 2,33 & 14,20 & 0,00 \\
\hline $\begin{array}{l}\text { Latossolo Vermelho- } \\
\text { Amarelo álico }\end{array}$ & 4,73 & 0,90 & 10,00 & 0,14 & 0,03 & 1,20 & 5,30 & 0,20 & 1,40 & 5,50 & 3,60 & 85,70 \\
\hline
\end{tabular}

pH em água - Relação 1: 2,5; P e K - Extrator Mehlich 1; $\mathrm{Ca}^{2+}, \mathrm{Mg}^{2+}$ e $\mathrm{Al}^{3+}-$ Extrator: $\mathrm{KCl} 1 \mathrm{~mol} \mathrm{~L} \mathrm{~L}^{-1} ; \mathrm{H}+\mathrm{Al}-\mathrm{Extrator}$ acetato de cálcio 0,5 mol L-1 $-\mathrm{pH} 7,0 ; \mathrm{SB}=$ soma de bases; $(\mathrm{t})=$ Capacidade de troca catiônica efetiva; $(\mathrm{T})=$ capacidade de troca catiônica, pH 7,$0 ; \mathrm{V}=$ saturação por bases; e $\mathrm{m}=$ saturação por alumínio.

R. Árvore, Viçosa-MG, v.32, n.2, p.193-201, 2008 
em que:

$\mathrm{NC}=$ necessidade de calagem em toneladas por hectare;

$\mathrm{V}_{1}=$ porcentagem de saturação por bases original do solo, conforme análise;

$\mathrm{V}_{2}=$ porcentagem de saturação por bases desejada; e

$\mathrm{T}=$ capacidade de troca catiônica, a pH 7,0.

A adubação de base foi realizada logo após o período de incubação e dois dias antes da semeadura, tomandose como referência a adubação utilizada por Passos (1994), em experimento com mudas de algaroba. Foram adicionados, via solução, $300 \mathrm{mg} \mathrm{dm}^{-3} \mathrm{de} \mathrm{P}, 100 \mathrm{mg}$ $\mathrm{dm}^{-3} \mathrm{de} \mathrm{K}, 40 \mathrm{mg} \mathrm{dm}^{-3} \mathrm{de} S$ e $100 \mathrm{mg} \mathrm{dm}^{-3} \mathrm{de} \mathrm{N}$, usandose como fontes o $\mathrm{NaH}_{2} \mathrm{PO}_{4} \cdot \mathrm{H}_{2} \mathrm{O}, \mathrm{KH}_{2} \mathrm{PO}_{4}, \mathrm{~K}_{2} \mathrm{SO}_{4} \mathrm{e}$ $\mathrm{NH}_{4} \mathrm{NO}_{3}$ Foi aplicada também, como adubação de base, solução de micronutrientes nas seguintes doses: 0,81

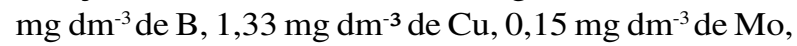
3,66 $\mathrm{mg} \mathrm{dm}^{-3}$ de Mn e 4,0 $\mathrm{mg} \mathrm{dm}^{-3} \mathrm{de} \mathrm{Zn}$, com as seguintes fontes, respectivamente: $\mathrm{H}_{3} \mathrm{BO}_{3}, \mathrm{CuSO}_{4} .5 \mathrm{H}_{2} \mathrm{O}$, $\left(\mathrm{NH}_{4}\right)_{6} \mathrm{Mo}_{7} \mathrm{O}_{24} \cdot 4 \mathrm{H}_{2} \mathrm{O}, \mathrm{MnCl}_{2} \cdot \mathrm{H}_{2} \mathrm{O}$ e $\mathrm{ZnSO}_{4} \cdot 7 \mathrm{H}_{2} \mathrm{O}$, de acordo com Alvarez V. (1974).

Como adubação de cobertura foram aplicados 20 $\mathrm{mg} \mathrm{dm}{ }^{-3}$ de $\mathrm{N}$ aos 30 e 60 dias após a germinação das sementes, usando-se como fonte $\mathrm{NH}_{4} \mathrm{NO}_{3}$. Aos 90 dias, além do $\mathrm{N}$, foram aplicados também $55,8 \mathrm{mg} \mathrm{dm}^{-3} \mathrm{de}$ $\mathrm{K}$, utilizando-se como fonte o $\mathrm{KNO}_{3}$, de acordo com Garcia (1986).

Para a produção das mudas, cada vaso de polietileno rígido de $0,17 \mathrm{~m}$ de altura por $0,15 \mathrm{~m}$ de diâmetro e capacidade para $2,1 \mathrm{~kg}$ de solo recebeu 10 sementes. Aos 15 dias após a emergência das plântulas, foi efetuado um primeiro raleio, deixando-se duas plantas por vaso, e aos 30 dias um segundo raleio foi realizado, deixandose apenas uma planta por vaso.

Aos 120 dias após a semeadura foram medidos a altura (H) e o diâmetro do coleto (DC) de todas as plantas. A altura foi medida com uma régua de precisão de $0,1 \mathrm{~cm}$, e para a medição do diâmetro do coleto utilizouse um paquímetro digital com precisão de $0,01 \mathrm{~mm}$. As plantas foram então divididas em parte aérea e raízes, lavadas em água destilada, colocadas em sacos de papel e postas a secar em estufa a $65^{\circ} \mathrm{C}$, por $72 \mathrm{~h}$, com circulação de ar forçada. Após a secagem, o material foi pesado em balança analítica com precisão de $0,01 \mathrm{~g}$ para determinação do peso de matéria seca da parte aérea (PMSPA) e peso de matéria seca das raízes (PMSR).

Na determinação da qualidade das mudas, foram avaliados, além das características mencionadas anteriormente, o peso de matéria seca total (PMST) e as relações entre a altura da parte aérea e o diâmetro do coleto (H/DC), altura da parte aérea e o peso de matéria seca da parte aérea (H/PMSPA), peso de matéria seca da parte aérea e o peso de matéria seca das raízes (PMSPA/PMSR) e o índice de qualidade de Dickson (IQD), segundo a metodologia utilizada por Gomes (2001), em que IQD = PMST/(H/DC + PMSPA/PMSR $)$.

O experimento foi constituído num delineamento em blocos ao acaso com quatro repetições, sendo cada vaso considerado uma unidade experimental. Os dados foram submetidos às análises estatísticas por meio de análises de variância e de regressão, utilizando-se o programa SAS (Sistema para Análises Estatísticas).

\section{RESULTADOS E DISCUSSÃO}

O tratamento que não recebeu a mistura corretiva apresentou as menores médias para todas as características estudadas nos três substratos utilizados (Quadro 3). Esses resultados são contrários aos encontrados por Medeiros e Hoppe (2002) para Papilus deltoides (álamo), onde a calagem não se mostrou necessária em condições de casa de vegetação, tendo o tratamento sem calcário apresentado a maior porcentagem de sobrevivência e as melhores médias dos parâmetros observados: diâmetro do coleto, altura do broto e peso de matéria seca da parte aérea.

Quadro 2 - Valores de saturação por bases original dos solos e tratamentos aplicados Table 2 - Original base saturation values of the soils and treatments applied

\begin{tabular}{|c|c|c|c|c|}
\hline \multirow[t]{2}{*}{ Solo } & \multicolumn{4}{|c|}{ Saturação por Bases (\%) } \\
\hline & Original & Tratamento 1 & Tratamento 2 & Tratamento 3 \\
\hline Argissolo Vermelho-Amarelo & 39,40 & 50,00 & 60,00 & 70,00 \\
\hline Latossolo Vermelho-Amarelo distrófico & 14,20 & 30,00 & 50,00 & 70,00 \\
\hline Latossolo Vermelho-Amarelo álico & 3,60 & 25,00 & 45,00 & 65,00 \\
\hline
\end{tabular}


Quadro 3 - Médias de altura (H), diâmetro do coleto (DC), peso de matéria seca da parte aérea (PMSPA), peso de matéria seca das raízes (PMSR) e peso de matéria seca total (PMST) de mudas de Machaerium nictitans, em resposta à elevação da saturação por bases do substrato aos 120 dias após a semeadura

Table 3 - Height averages $(H)$, stem diameter $(D C)$, dry matter weight of the aerial part (PMSPA), dry matter weight of the roots (PMSR), and total dry matter weight (PMST) of Machaerium nictitans seedlings in response to increased saturation by substratum base saturation at 120 days after planting

\begin{tabular}{|c|c|c|c|c|c|c|}
\hline & Saturação & Altura & DC & PMSPA & PMSR & PMST \\
\hline & $(\%)$ & $(\mathrm{cm})$ & $(\mathrm{mm})$ & & (g) & \\
\hline \multirow[t]{4}{*}{ Argissolo Vermelho-Amarelo } & 39,4 & 32,38 & 4,76 & 4,38 & 1,01 & 5,39 \\
\hline & 50 & 37,50 & 5,32 & 5,04 & 1,29 & 6,33 \\
\hline & 60 & 45,50 & 5,94 & 8,22 & 2,22 & 10,44 \\
\hline & 70 & 34,38 & 5,16 & 4,84 & 1,73 & 6,57 \\
\hline \multirow[t]{4}{*}{ Latossolo Vermelho-Amarelo distrófico } & 14,2 & 10,25 & 3,06 & 0,67 & 0,23 & 0,90 \\
\hline & 30 & 26,00 & 3,66 & 1,22 & 0,65 & 1,87 \\
\hline & 50 & 19,75 & 4,31 & 1,18 & 0,67 & 1,85 \\
\hline & 70 & 20,13 & 3,81 & 2,06 & 0,78 & 2,84 \\
\hline \multirow[t]{4}{*}{ Latossolo Vermelho-Amarelo álico } & 3,6 & 13,50 & 3,51 & 1,09 & 0,28 & 1,37 \\
\hline & 25 & 40,00 & 5,02 & 4,99 & 1,48 & 6,47 \\
\hline & 45 & 32,88 & 5,28 & 4,86 & 1,40 & 6,26 \\
\hline & 65 & 24,75 & 3,99 & 3,33 & 0,89 & 4,22 \\
\hline
\end{tabular}

Comparando-se os valores médios de altura alcançados pelas mudas de Machaerium nictitans com outras duas leguminosas, esses foram inferiores aos encontrados por Bernardino et al. (2005) para angico-vermelho aos 100 dias após a semeadura e superiores aos observados por Gomes et al. (2004) para angico-branco aos 170 dias após a semeadura, sendo os valores de diâmetro do coleto semelhantes aos encontrados por esses pesquisadores (Quadros 3 e 4). Gomes (2001) ressaltou que, para os resultados serem semelhantes, tanto as espécies quanto os métodos de produção de mudas e as técnicas de viveiros utilizados deverão ser observados.

Quadro 4 - Médias das relações entre as características altura e diâmetro do coleto (H/DC), altura e peso de matéria seca da parte aérea (H/PMSPA), peso de matéria seca da parte aérea e peso de matéria seca das raízes (PMSPA/PMSR) e do índice de qualidade de Dickson de mudas de Machaerium nictitans, em resposta a saturação por bases do substrato aos 120 dias após a semeadura

Table 4 -Averages of the relations between height and stem diameter characteristics $(H / D C)$, height and dry matter weight of the aerial part (H/PMSPA), dry matter weight of the aerial part and of the roots (PMSPA/PMSR) and of the Dickson's quality index of Machaerium nictitans seedlings in response to substratum base saturation at 120 days after planting

\begin{tabular}{lccccc}
\hline & Saturação $(\%)$ & H/DC & H/PMSPA & PMSPA/PMSR & IQD \\
\hline Argissolo Vermelho-Amarelo & 39,4 & 6,80 & 7,39 & 4,34 & 0,48 \\
& 50 & 7,05 & 7,44 & 3,91 & 0,58 \\
& 60 & 7,66 & 5,54 & 3,70 & 0,92 \\
& 70 & 6,66 & 7,10 & 2,80 & 0,69 \\
\hline Latossolo Vermelho-Amarelo distrófico & 14,2 & 3,35 & 15,30 & 2,91 & 0,14 \\
& 30 & 7,10 & 21,31 & 1,88 & 0,21 \\
& 50 & 4,58 & 16,74 & 1,76 & 0,29 \\
\hline Latossolo Vermelho-Amarelo álico & 70 & 5,28 & 9,77 & 2,64 & 0,36 \\
& 3,6 & 3,85 & 12,39 & 3,89 & 0,18 \\
& 25 & 7,97 & 8,02 & 3,37 & 0,57 \\
& 45 & 6,23 & 6,77 & 3,47 & 0,65 \\
& 65 & 6,20 & 7,43 & 3,74 & 0,42 \\
\hline
\end{tabular}

R. Árvore, Viçosa-MG, v.32, n.2, p.193-201, 2008 
No Latossolo Vermelho-Amarelo distrófico, somente as características diâmetro do coleto, peso de matéria seca das raízes e índice de qualidade de Dickson se mostraram significativamente afetados pela elevação da saturação por bases do substrato (Quadros 5 e 6). Esses resultados podem ser relacionados com os encontrados por Schimidt (1995), em que a calagem afetou diretamente a relação entre altura e matéria seca, tendo em vista que esta promoveu maiores crescimentos na altura das mudas de E. camaldulensis. A calagem, além de corrigir a acidez do solo, estimula a atividade microbiana, melhora a fixação de $\mathrm{N}_{2}$ pelas leguminosas e, ainda, aumenta a disponibilidade de nutrientes como Ca e Mg (CFSEMG, 1999).

Quadro 5 - Resumo da análise de variância de altura (H), diâmetro do coleto (DC), peso de matéria seca da parte aérea (PMSPA), peso de matéria seca das raízes (PMSR) e peso de matéria seca total (PMST) de mudas de Machaerium nictitans, em resposta à elevação da saturação por bases do substrato aos 120 dias após a semeadura

Table 5 - Summary of the variance analysis of height $(H)$, stem diameter $(D C)$, dry matter weight of the aerial part (PMSPA) and of the roots (PMSR) and total dry matter weight (PMST) of Machaerium nictitans seedlings in response to increased substratum base saturation at 120 days after sowing

\begin{tabular}{|c|c|c|c|c|c|c|c|}
\hline & \multirow[b]{2}{*}{$\mathrm{FV}$} & \multirow[b]{2}{*}{ GL } & \multicolumn{5}{|c|}{ Quadrado Médio } \\
\hline & & & $\mathrm{H}$ & $\mathrm{DC}$ & PMSPA & PMSR & PMST \\
\hline Argissolo & Saturação por bases & 3 & $133,354^{\mathrm{ns}}$ & $0,977^{\mathrm{ns}}$ & $12,337^{\mathrm{ns}}$ & $1,121^{\mathrm{ns}}$ & $19,941^{\mathrm{ns}}$ \\
\hline Vermelho- & Bloco & 3 & $103,104^{\mathrm{ns}}$ & $0,230^{\mathrm{ns}}$ & $1,709^{\mathrm{ns}}$ & $0,166^{\mathrm{ns}}$ & $2,830^{\mathrm{ns}}$ \\
\hline \multirow[t]{2}{*}{ Amarelo } & Resíduo & 9 & 334,896 & 1,373 & 11,780 & 0,744 & 17,880 \\
\hline & $\mathrm{CV}(\%)$ & & 48,9 & 22,1 & 61,1 & 55,2 & 58,9 \\
\hline Latossolo & Saturação por bases & 3 & $169,849^{\text {ns }}$ & $1,060 *$ & $1,315^{\mathrm{ns}}$ & $0,234^{*}$ & $2,497^{\mathrm{ns}}$ \\
\hline Vermelho- & Bloco & 3 & $21,682^{\mathrm{ns}}$ & $0,430^{\mathrm{ns}}$ & $1,234^{\mathrm{ns}}$ & $0,008^{\mathrm{ns}}$ & $1,425^{\mathrm{ns}}$ \\
\hline \multirow{2}{*}{ Amarelo distrófico } & Resíduo & 9 & 208,404 & 0,222 & 1,085 & 0,033 & 1,382 \\
\hline & $\mathrm{CV}(\%)$ & & 75,9 & 12,7 & 81,3 & 31,1 & 61,2 \\
\hline Latossolo & Saturação por bases & 3 & $517,849 *$ & $2,805^{\mathrm{ns}}$ & $13,134 *$ & $1,227 *$ & $22,371^{*}$ \\
\hline Vermelho- & Bloco & 3 & $92,182^{\mathrm{ns}}$ & $0,596^{\mathrm{ns}}$ & $0,674^{\mathrm{ns}}$ & $0,233^{\mathrm{ns}}$ & $1,677^{\mathrm{ns}}$ \\
\hline \multirow[t]{2}{*}{ Amarelo álico } & Resíduo & 9 & 113,765 & 0,737 & 2,347 & 1,192 & 3,516 \\
\hline & $\mathrm{CV}(\%)$ & & 38,4 & 19,3 & 43 & 43,3 & 41 \\
\hline
\end{tabular}

* Significativo a $5 \%$ de probabilidade, pelo teste F. ${ }^{\text {ns }}$ Não-significativo a $5 \%$ de probabilidade, pelo teste F.

Quadro 6 - Resumo da análise de variância das relações entre altura e diâmetro do coleto (H/DC), altura e peso de matéria seca da parte aérea (H/PMSPA), peso de matéria seca da parte aérea e peso de matéria seca das raízes (PMSPA/ PMSR) e do índice de qualidade de Dickson de mudas de Machaerium nictitans, em resposta à elevação da saturação por bases do substrato aos 120 dias após a semeadura

Table 6 - Summary of the variance analysis of the relation between height and stem diameter $(H / D C)$, height and dry matter weight of the aerial part (H/PMSPA), dry matter weight of the aerial part and of the roots (PMSPA/PMSR) and the Dickson's quality index of Machaerium nictitans seedlings in response to increased substratum base saturation at 120 days after sowing

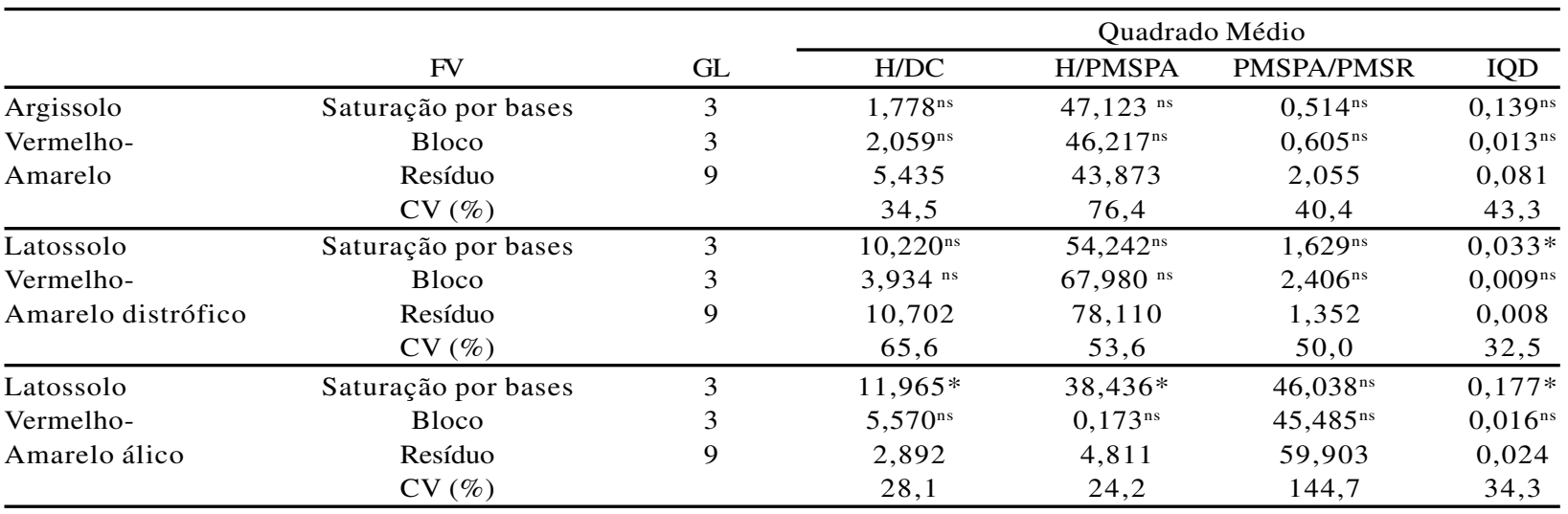

* Significativo a 5\% de probabilidade, pelo teste F. ${ }^{\text {ns }}$ Não-significativo a $5 \%$ de probabilidade, pelo teste $\mathrm{F}$. 
Quando foi utilizado o Latossolo Vermelho-Amarelo álico como substrato, todas as características estudadas, com exceção do diâmetro do coleto e da relação entre o peso de matéria seca da parte aérea e peso de matéria seca das raízes, foram significativamente influenciadas pela saturação por bases (Quadros 5 e 6).

Nenhuma das características estudadas apresentou resposta significativa diante da elevação da saturação por bases do substrato para o Argissolo VermelhoAmarelo. Tal resultado pode estar relacionado ao fato de que os teores iniciais de $\mathrm{Ca}\left(1,74 \mathrm{cmol}_{\mathrm{c}} \mathrm{dm}^{-3}\right)$ e de $\mathrm{Mg}\left(0,17 \mathrm{cmol}_{\mathrm{c}} \mathrm{dm}^{-3}\right)$ presentes no substrato tenham sido suficientes para suprir a necessidade das plantas, pelo menos durante a fase de mudas. Esses resultados foram semelhantes aos encontrados por Baliero et al. (2001) em mudas de Acacia holocericea, por Bernardino et al. (2005) em mudas de angico-vermelho e por Reis et al. (1997) em mudas de jacarandá-da-bahia.

Outro motivo da falta de resposta das mudas de Machaerium nictitans em função da elevação da saturação por bases do Argissolo pode estar relacionado ao teor de saturação por bases inicial do solo $(39,4 \%)$ e aos baixos teores de $\mathrm{Al}^{3+}\left(0,0 \mathrm{cmol}_{\mathrm{c}} \mathrm{dm}^{-3}\right)$.

O índice de qualidade de Dickson teve comportamento diferenciado diante da elevação da saturação do substrato. No Latossolo Vermelho-Amarelo distrófico, o comportamento foi do tipo linear, com os maiores valores ocorrendo na máxima saturação testada (70\%), já no Latossolo Vermelho-Amarelo álico esse comportamento foi do tipo quadrático, com o maior valor na saturação por bases de $40 \%$ (Figura 1A).

O quociente entre a altura e peso de matéria seca da parte aérea no Latossolo Vermelho-Amarelo álico atingiu o menor valor na saturação por bases de $45 \%$ (Figura 1B). Gomes (2001) ressaltou que esse índice não é normalmente utilizado como padrão de qualidade de mudas, mas é um bom índice para predizer a capacidade de sobrevivência da muda no campo, ressaltando-se que, quanto menor o seu valor, maior essa capacidade. Esse mesmo autor ainda citou que, quanto maior o índice de qualidade de Dickson, maior o padrão de qualidade das mudas.

No Latossolo Vermelho-Amarelo distrófico, o peso de matéria seca das raízes atingiu os maiores valores entre as saturações de 60 e $70 \%$, já o diâmetro do coleto assumiu comportamento quadrático, com os maiores valores na saturação de $50 \%$ (Figura 2).

No Latossolo Vermelho-Amarelo álico, todas as características afetadas significativamente pela elevação da saturação por bases do substrato obedeceram a um comportamento do tipo quadrático, com os maiores valores ocorrendo próximo à saturação de 40\% (Figura 3).

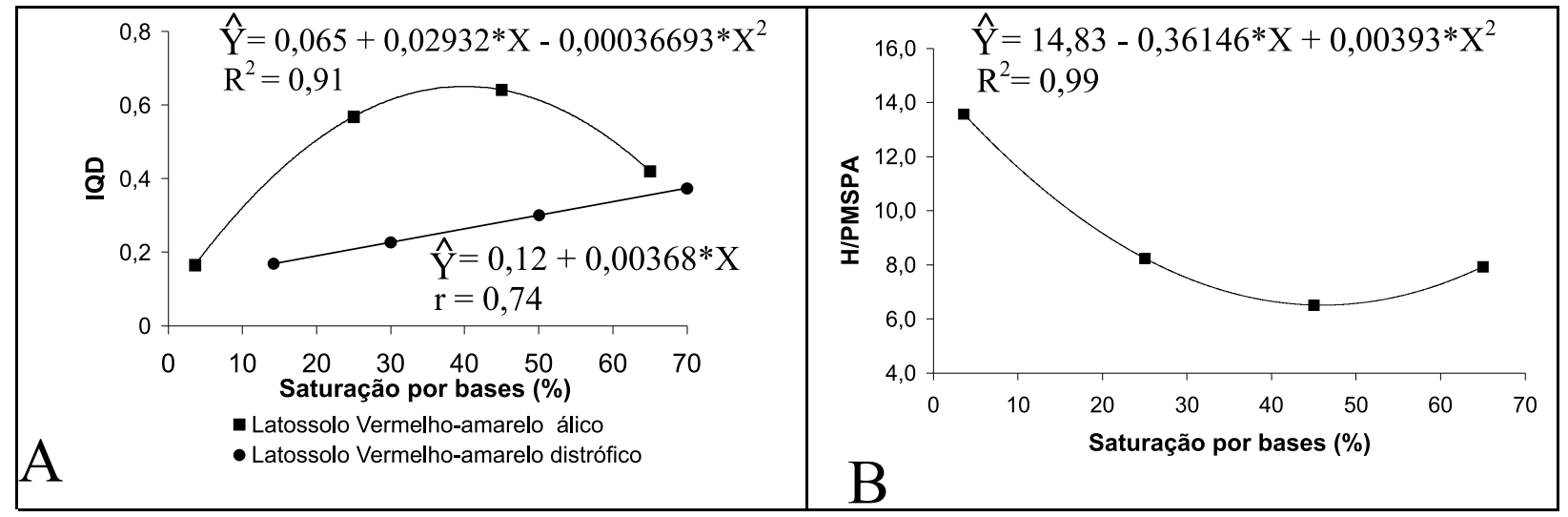

Figura 1 - Índice de qualidade de Dickson dos latossolos usados no experimento (1A) e relação entre a altura da parte aérea e o peso de matéria seca da parte aérea em Latossolo Vermelho-amarelo álico (1B) de mudas de Machaerium nictitans, em função da saturação por bases do substrato aos 120 dias após a semeadura.

Figure 1-Dickson's quality index of Latosols (1A) and relation between height and dry matter weight of the aerial part in Red-Yellow alic Latosol (1B) of Machaerium nictitans seedlings due to substratum base saturation at 120 days after sowing.

R. Árvore, Viçosa-MG, v.32, n.2, p.193-201, 2008 


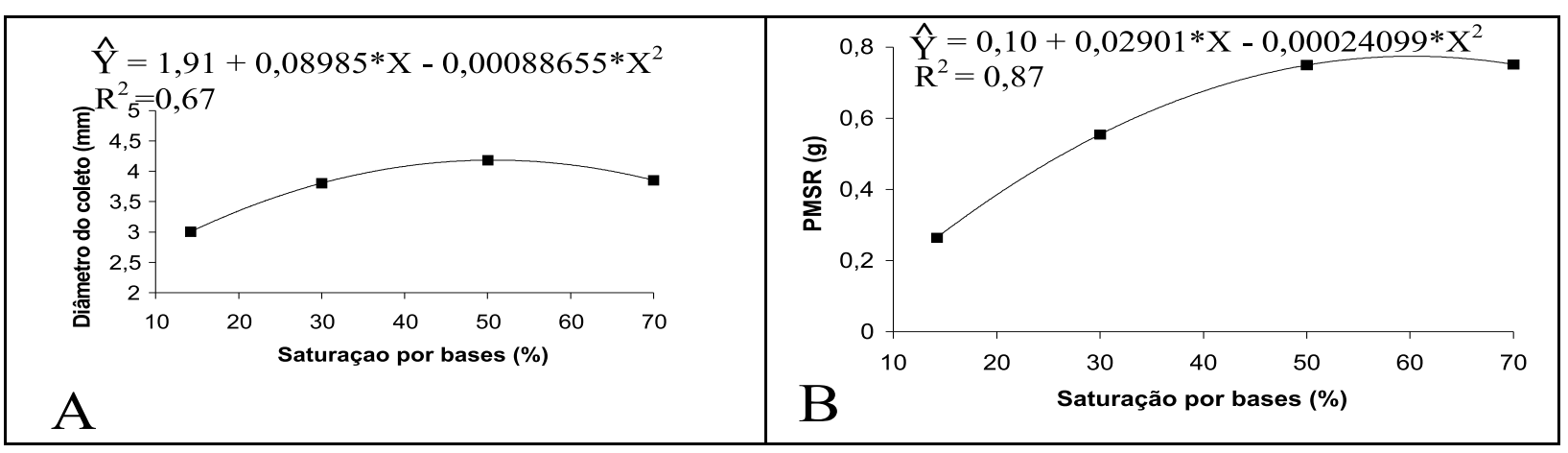

Figura 2 - Diâmetro do coleto (2A) e peso de matéria seca das raízes (2B) de mudas de Machaerium nictitans produzidas em Latossolo Vermelho-Amarelo distrófico, em função da saturação por bases do substrato aos 120 dias após a semeadura.

Figure 2 - Stem diameter (2A) and dry matter weight of the roots $(2 B)$ of Machaerium nictitans seedlings produced in Red-Yellow Dystrophic Latosol due to substratum base saturation at 120 days after sowing.
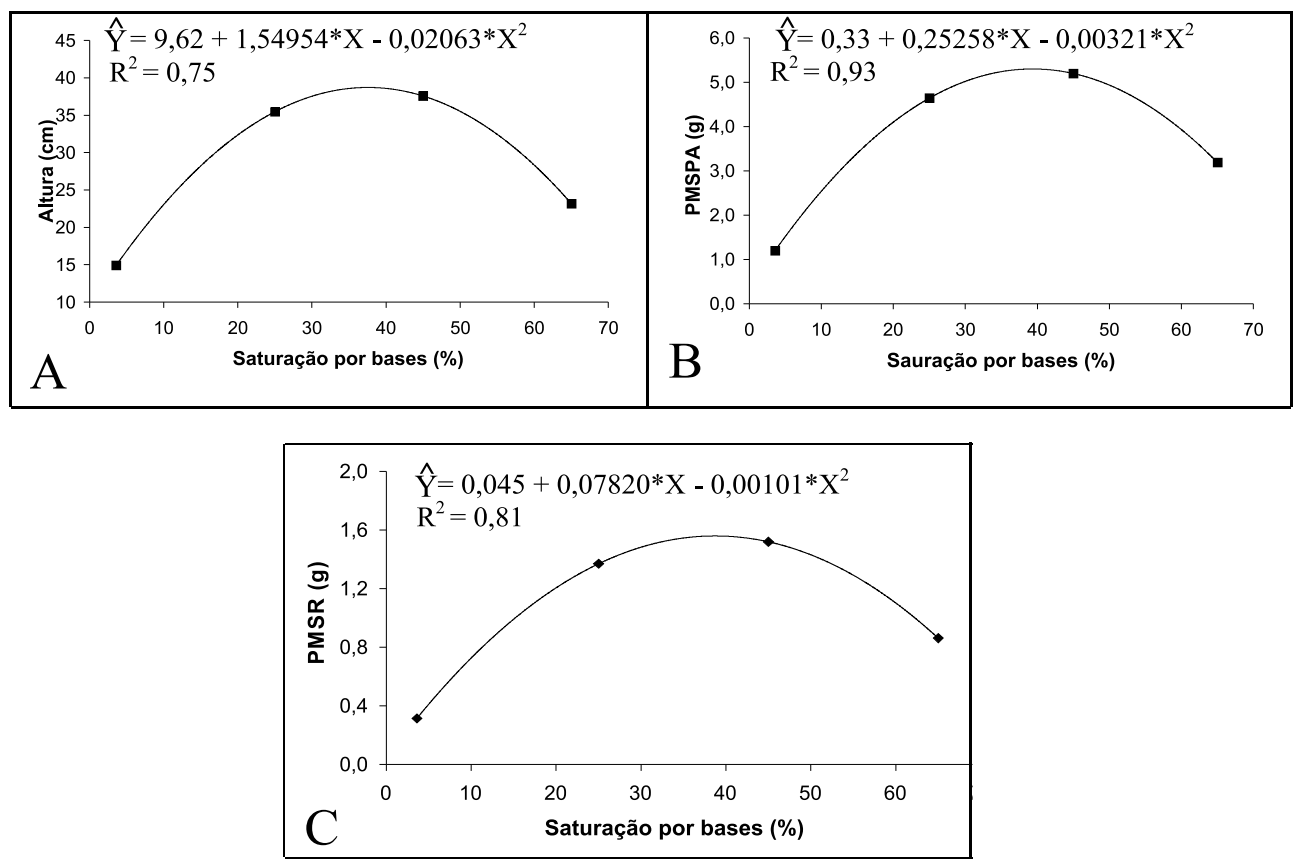

Figura 3 - Altura da parte aérea (3A), peso de matéria seca da parte aérea (3B) e peso de matéria seca das raízes (3C) de mudas de Machaerium nictitans produzidas em Latossolo Vermelho-Amarelo álico, em função da saturação por bases do substrato aos 120 dias após a semeadura.

Figure 3 - Height of the aerial part (3A), dry matter weight of the aerial part (3B) and of the roots (3C) of Machaerium nictitans seedlings produced in Red-Yellow alic Latosol due to substratum base saturation at 120 days after planting.

Comparando-se o peso de matéria seca total das mudas de Machaerium nictitans nos três solos utilizados como substrato, é possível observar que, no Latossolo Vermelho-Amarelo álico, a exemplo das demais características influenciadas pela elevação da saturação por bases, esta obedeceu a um comportamento quadrático com os maiores valores próximo à saturação de $40 \%$. Já no Argissolo e no Latossolo Vermelho-Amarelo distrófico a elevação da saturação por bases não exerceu efeito significativo sobre essa característica, sendo o maior valor igual à média (Quadro 7 e Figura 4). 


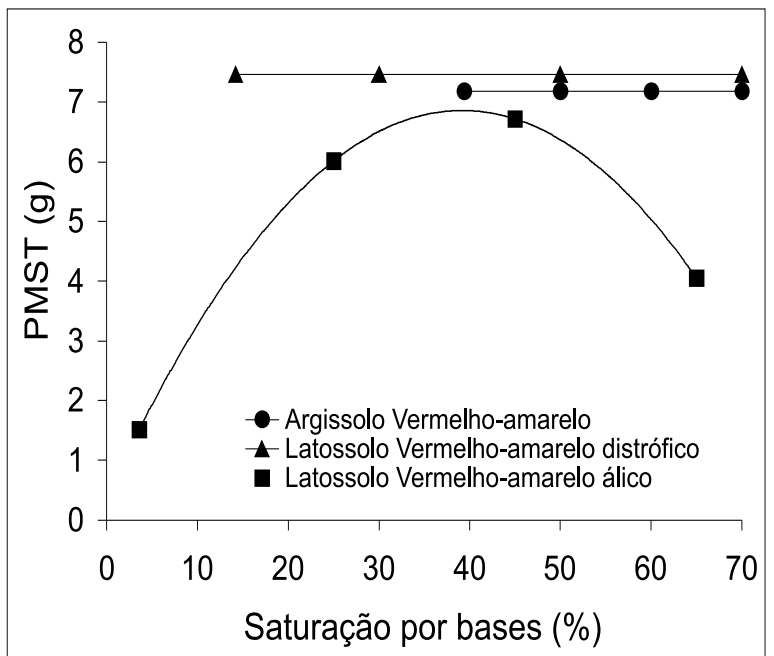

Figura 4-Peso de matéria seca total das mudas de Machaerium nictitans produzidas em três diferentes solos, em função da saturação por bases do substrato aos 120 dias após a semeadura.

Figure 4-Total dry matter weight of Machaerium nictitans seedlings produced in three different soils due to substratum base saturation at 120 days after planting.

Quadro 7 - Equações de regressão da característica peso de matéria seca total de mudas de Machaerium nictitans em função da saturação por bases do substrato aos 120 dias após a semeadura

Table 7-Regression equations for the characteristic total dry matter weight of Machaerium nictitans seedlings due to substratum base saturation at 120 days after planting

\begin{tabular}{lc}
\hline Solo & Equação de Regressão \\
\hline Argissolo Vermelho-Amarelo & $\hat{Y}=\bar{y}$ \\
\hline Latossolo Vermelho- & $\hat{Y}=\bar{y}$ \\
Amarelo distrófico & \\
\hline Latossolo Vermelho- & $\hat{\mathrm{Y}}=0,38+0,33078 * \mathrm{X}$ \\
Amarelo álico & $-0,00422^{*} \mathrm{X}^{2} \mathrm{R}^{2}=0,90$ \\
\hline
\end{tabular}

* Significativo a $5 \%$ de probabilidade, pelo teste " $\mathrm{t}$ ".

\section{CONCLUSÕES}

As melhores mudas de Machaerium nictitans no Argissolo Vermelho-Amarelo foram obtidas na saturação por bases de $60 \%$, no Latossolo VermelhoAmarelo distrófico na saturação por bases $70 \%$ e no Latossolo Vermelho-Amarelo álico na saturação por bases de $40 \%$.

R. Árvore, Viçosa-MG, v.32, n.2, p.193-201, 2008

\section{AGRADECIMENTOS}

Os autores agradecem à CAPES, pela concessão de bolsas de estudos; ao CNPq pela concessão de bolsas de produtividade em pesquisa, e ao projeto PRODETAB 130-02/01, pelo financiamento do presente trabalho.

\section{REFERÊNCIAS}

ALVAREZ V., V. H. Equilíbrio de formas disponíveis de fósforo e enxofres em dois latossolos de Minas Gerais. 1974. 125f. Dissertação (Mestrado em Solos e Nutrição de Plantas) - Universidade Federal de Viçosa, Viçosa, MG, 1974.

BAILIERO, F. C.; OLIVEIRA, I. G.; DIAS, L. E. Formação de mudas de Acacia holocericea. Resposta à calagem, fósforo, potássio e enxofre. Revista Árvore, v.25, n.2, p.183-192, 2001.

BERNARDINO, D. C. S. et al. Crescimento e qualidade de mudas de Anadenanthera macrocarpa (Benth.) Brenan em resposta à saturação por bases do substrato. Revista Árvore, v.29, n.6, p.863-870, 2005.

CAMARGO, O. A. et al. Alterações de atributos químicos do horizonte superficial de um latossolo e um podzólico com a calagem. Sciencia Agrícola, v.54, n.1, p. 1-8, 1997.

COMISSÃO DE FERTILIDADE DO SOLO DO ESTADO DE MINAS GERAIS - CFSEMG. Recomendações para o uso de corretivos e fertilizantes em Minas Gerais. 5 a aproximação. Viçosa, MG: 1999. 359p.

FURTINI NETO, A. E. et al. Acidez do solo, crescimento e nutrição de algumas espécies arbóreas, na fase de muda. Cerne, v.5, n.2, p.1-12, 1999.

GARCIA, N. C. P. Efeitos da calagem e de níveis de fósforo sobre o crescimento e composição mineral da mudas de cedro (Cedrela fissilis Vell.). 1986. 40f. Dissertação (Mestrado em Ciência Florestal)Universidade Federal de Viçosa, Viçosa-MG, 1986. 
GOMES, K. C. O. et al. Influência da saturação por bases no crescimento de mudas de angico branco. Revista Árvore, v.28, n.6, p.785-792, 2004.

GOMES, J. M. Parâmetros morfológicos na avaliação da qualidade de mudas de Eucalyptus grandis, produzidas em diferentes tamanhos de tubete $e$ dosagens de N-P-K. 2001. 166f.. Tese (Doutorado em Ciência Florestal) - Universidade Federal de Viçosa, Viçosa, MG, 2001.

LORENZI, H. Árvores brasileiras. Nova Odessa: Plantarum, 1992. 352p.

MEDEIROS, J. G. S.; HOPPE, J. M. Efeito da aplicação de calcário em estacas de populus deltoides Bartr. Ex Marsh cultivadas em vaso. Ciência Florestal, v.12, n.2, p.161-167, 2002.
PASSOS, M. A. A. Efeito da calagem e de fósforo no crescimento inicial da algaroba (Prosopis juliflora (SW) DC). 1994. 57f.. Tese (Doutorado em Fitotecnia) Universidade Federal de Viçosa, Viçosa, MG, 1994.

REIS, M. G. F. et al. Exigências nutricionais de mudas de Dalbergia nigra (Vell.) Fr. Allem (Jacarandá-da-Bahia) produzidas em dois níveis de sombreamento. Revista Árvore, v.21, n.4, p.463-471, 1997.

SCHMIDT, D. V. C. Crescimento de mudas de Eucalyptus camaldulensis $e$. Eucalyptus grandis em resposta à fertilização potássica e a calagem. 1995. 57f. Dissertação (Mestrado em Ciência Florestal) - Universidade Federal de Viçosa, Viçosa, MG, 1995. 